\title{
The Synergistic Effect of Hydrogen and Strain on Electronic
}

\section{Properties of $\mathrm{p}-\mathrm{Cr}_{2} \mathrm{O}_{3} / \mathrm{n}-\mathrm{Fe}_{2} \mathrm{O}_{3}$ Interface}

Zhishan Mi, ${ }^{\mathrm{a}, \mathrm{b}}$ Li Chen, ${ }^{* a, \mathrm{c}}$ Hongmei Liu, ${ }^{\mathrm{c}}$ Changmin Shi, ${ }^{\mathrm{c}}$ Dongchao Wang, ${ }^{\mathrm{c}}$ Xiaolong Li, ${ }^{\mathrm{c}}$ Kefu $\mathrm{Gao}^{\mathrm{b}, \mathrm{c}}$ and Lijie Qiao, ${ }^{* * \mathrm{~b}}$

${ }^{a}$ School of Electronic and Information Engineering (Department of Physics), Qilu University of Technology, Jinan, 250353, PR China

${ }^{\mathrm{b}}$ Beijing Advanced Innovation Center for Materials Genome Engineering, Corrosion and Protection Center, University of Science and Technology Beijing, Beijing, 100083, PR China

${ }^{\mathrm{c}}$ Institute of Condensed Matter Physics, Linyi University, Shandong, 276000, PR China

\section{Corresponding Authors}

*E-mail: chenli@1yu.edu.cn (L.C.).

*E-mail: lqiao@ustb.edu.cn (L.Q.).

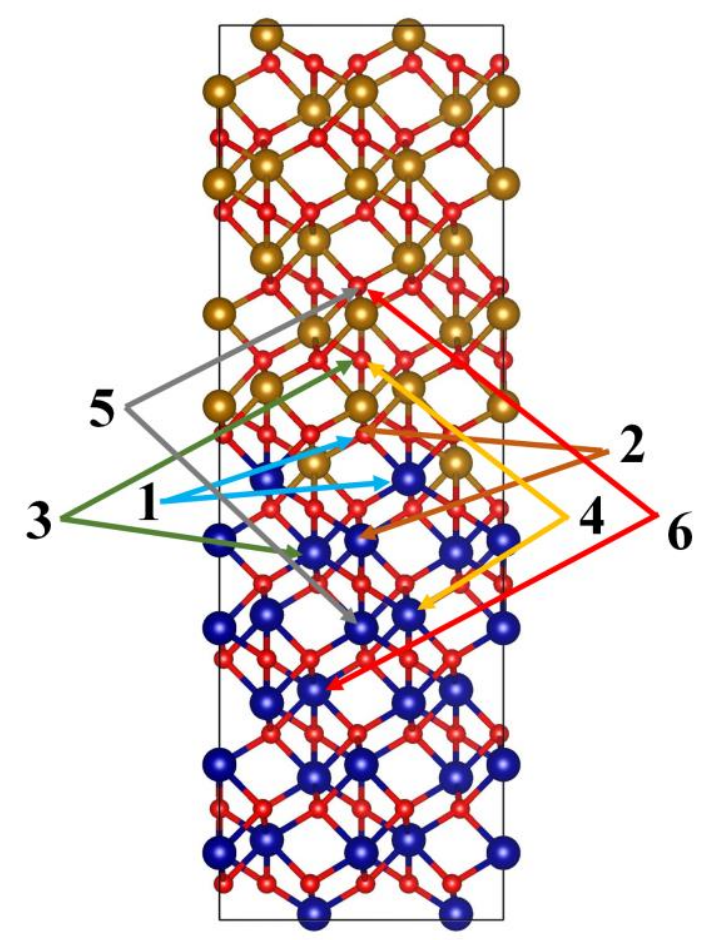

\begin{tabular}{|c|c|}
\hline Position & \multicolumn{1}{c|}{ Total energy (eV) } \\
\hline 1 & -1868.3168 \\
\hline 2 & -1867.7502 \\
\hline 3 & -1867.3200 \\
\hline 4 & -1867.0925 \\
\hline 5 & -1867.0567 \\
\hline 6 & -1866.9508 \\
\hline
\end{tabular}

Figure S1. The Cr vacancy and O vacancy for interface structure in different position.

When the Cr vacancy and $\mathrm{O}$ vacancy are at the interface, the $\mathrm{p}-\mathrm{Cr}_{2} \mathrm{O}_{3} / \mathrm{n}-\mathrm{Fe}_{2} \mathrm{O}_{3}$ interface structure is the most stable with the lowest total energy. 


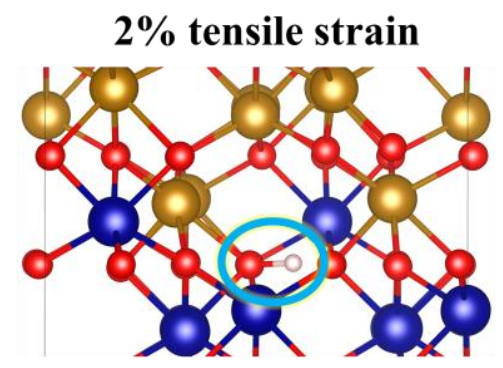

$2 \%$ compressive strain

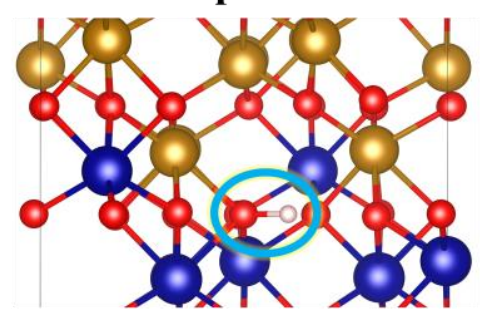

\begin{tabular}{|c|c|c|}
\hline & H-O bond & H charge tranfer \\
\hline tensile strain & $1.01 \AA$ & 0.70 \\
\hline compressive strain & $1.03 \AA$ & 0.68 \\
\hline
\end{tabular}

Figure S2. The structural analysis and $\mathrm{H}$ charge transfer under $2 \%$ tensile and compressive strain. 